\title{
Exploration on Planning System and Planning Method of Urban Ventilation Corridor
}

(Zhangzhou city planning and Design Institute, Zhangzhou City, Fujian, 363000, China)

\section{Research Background}

In recent years, with rapid urbanization and expanding urban scale, city load is getting heavier and the quality of the urban environment is declining $^{[1]}$, so that climate problems including high temperature and heat wave, air pollution and haze, etc, are becoming increasingly prominent to become chronic diseases preventing cities from healthy development in China. In particular, haze sieges happens a lot in recent years. In the background of "Waiting for wind", prospective urban climate planning is an important choice to solve practical problems. Ventilation corridor planning has been put on the agenda in many cities and Zhangzhou in China also develops related planning in that context.

\section{Establishment of} Planning System

\subsection{Origin and Composition of Ventilation Corridor}

Wind is known as airflow. Uneven temperature on the surface of earth due to the light and heat from the sun results in the air where its hotter has smaller density to become lighter, expanding and rising to break the balance so that air flows in the complex surface environment form the changing wind. Applying the definition to cities (complex surface environment), we know that wind in the city is also the airflow generated between the inner city and its external environment.

For the purpose of formation and flow of wind, we introduce the concept of "Ventilation Corridor". "Ventilation Corridor" comes from "Ventilationsbahn" in German, consisting of "Ventilations" and "Bahn" meaning "ventilation" and "corridor" respectively. Germany scholars firstly put forward the evaluation criteria on climate function on the underlying surface based on the local circulation rule to divide the urban ventilation system into interaction space, compensation space and air guide channel ${ }^{[2]}$.

Based on the formation of wind and the definition of "Ventilation Corridor", learning from the research products of some relevant scholars, this paper divide "the formation and working of wind" in the city into three sections, wind compensation area (formation area), wind active region and wind connection area (ventilation corridor). Through establishment of such three
Abstract: Aiming at more and more prominent climate problems including urban heat island and haze pollution, many cities develop studies on and compile urban ventilation corridor planning. As an emerging planning project, this paper explores to develop the urban ventilation system and the leading control factors oriented with practicability of urban ventilation corridor planning based on the establishment of Zhangzhou in China ventilation corridor planning, puts forward to corresponding control measures and develops the planning system and planning method of urban ventilation corridor.

Keywords: Ventilation system; Ventilation corridor; Compensation area and active region

Published on 30th Sept,2017

\footnotetext{
Corresponding Author

Yong Tao: Zhangzhou city

planning and Design Institute,

Zhangzhou City, Fujian, 363000,

China.38688245@.qq.com
} 
sections, to optimize urban layout, alleviate the heat island effect, improve the quality of wind environment and improve urban comfort to promote sustainable urban development.

\subsection{Types and Levels of} Ventilation Corridor Planning

Data indicates that urban planning in China has a late-starting research on urban ventilation corridor planning. In the late 1980 s to 1990 s, the idea of "Introducing fresh airflow into cities" was in paper on urban climatology, but related

researches were not developed in the discipline of urban planning. Since the turn of the century, although urbanists started calling for the planning and construction of the urban ventilation corridor, most of them just stayed on the level of qualitative analysis and principle proposal but lack of attention to and advantage of local circulation due to insufficient support from discipline of urban planning. ${ }^{[3]}$

In recent years, with the development of big data and maturing urban climate models, cities including Beijing, Wuhan, Hangzhou and Fuzhou, etc, develop ventilation corridor planning or thematic researches, but without unified understanding on content, composition, depth of planning and how to implement. The author talksabout the opinions combining the practical planning of ventilation corridor in Zhangzhou.

\subsection{Considerations on Some Questions}

2.3.1 Does the Ventilation Corridor Need to be Established?

Prevailing wind in winter and summer among many cities are different, the day and night wind direction is even changing in a day, during which, does it need to research and establish ventilation corridor? The ventilation corridor has many functions. Different cities have their own problems, so cities in the South and North have different primary factors to consider when establishing ventilation corridors. The answer will be clear only if people have the same original agreement to improve urban climate and the same recognition on the function of ventilation corridors improving the environment.

\subsubsection{Can the Ventilation Corridor be Established?}

The ventilation corridor isn't established, but goes with the flow complying with urban geographical conditions and under climate environment. Urban ventilation corridor shall be a prognosis and a choice implemented in planning in advance. The establishment of ventilation corridor planning shall be the choice of land and facilities in space to be set up without effect on proportion of land use and increasing investment. In Study on Multi-Scale Assessment Technology System of Atmospheric Environment Influence in Urban Planning and Application by Guangtao Wang, in terms of the climate atmospheric impact assessment for Olympic Park planning scheme, two schemes have different effects on atmospheric environment because of artificial lakes, green belts and architectural layout in the condition of reasonable land use and landscape design ${ }^{[4]}$

\subsubsection{How to Establish} Ventilation Corridors in the

\section{Built-Up Areas?}

How to manage and control the construction of ventilation corridors not on a blank paper but in old urban areas in particular where there are intensive buildings? When establishing ventilation corridor in old urban areas, it shall not or is not practicable to conduct mass-demolishing and mass-construction, but main part shall be arrange and control the areas the ventilation corridor goes through by combining the ventilation potential in the build-up area and add water and park supply to improve ventilation conditions when updating old urban area.

\subsection{Functions of Ventilation Corridor Planning}

\subsubsection{Construct the Frame Network of Ventilation System and Focus on Improvement of the Urban Ventilation Environment}

By studying basic theory of ventilation corridor and learning from experience of relevant cities and analysis of wind environment and climate status, this paper clearly delimits the ventilation corridor in the ventilation system, focuses on the improvement of ventilation environment in built-up area that covers improvement for old area and reservation for new area, controls the width of air guide channel and the roughness of underlying surface, reduce the hindrance to air circulation and improve the efficiency of compensation air mass.

\subsubsection{Protect the Area Where Cold Air Forms to Improve the Effect of Reduced Temperature of Rivers and Greenbelt}

Clearly delimit the compensation space in the ventilation system, determine the climate protection area and priority area, protect and develop the space and functions with function of climate suitability and improve the effect of reduced temperature of rivers and greenbelt through the protection of planning laws. ${ }^{[5]}$ 
2.4.3 Delimit the Interaction Space of Ventilation System to Relieve Heat Island Effect in High-Density Areas

Clearly delimit the interaction space in ventilation system, strictly control the development intensity in the process of urban development and promote the air flow in potential high-density areas to relieve heat island effect in downtown, high-density residence area and industrial area.

\section{Planning System Oriented by Implementation}

\subsection{Establish Macroscopic to} Mid-view Wind Environment Analysis Models

The foundation and support of ventilation corridor planning come from urban climatology, in particular, application of big data and studies on the basic ventilation corridor theory in recent years. All levels of influential factors and control key points will be gotten through data collection and the establishment of macroscopic to mid-view wind environment analysis models to provide technical and theoretical support to compile the planning.

In the practice in Zhangzhou, we receive great support from Professor Qingming Zhan and his team from Wuhan University.

\subsubsection{Macro-Level}

Based on topographic data, such as urban digital elevation model (DEM), plants and water combined with real-time meteorological data in global forecast system (GFS) provided by National Centers for Environmental Prediction
(NCEP), use Weather Research and Forecasting Model (WRF) for wind environment simulation ${ }^{[6]}$

In Zhangzhou project, build the WRF model to carry out climate simulation in the resolution of $1 \mathrm{~km}$ and time resolution of $1 \mathrm{~h}$ to have typical summer wind field map in Zhangzhou area (see Figure 1). And combine the simulation of downtown with WRF model to have measured wind speed and wind direction map to draw the wind field analysis chart. Through studies, clear and define that summer monsoon in downtown consists of land and sea breeze from southeast to northwest and mountain and valley wind from south to north, in which, the south wind is dominant on the west side of Xiangcheng District and at Yuanshan New town while the southeast wind is dominant on the east side of Xiangcheng District and at Longwen District and Taiwanese Investment Zone.

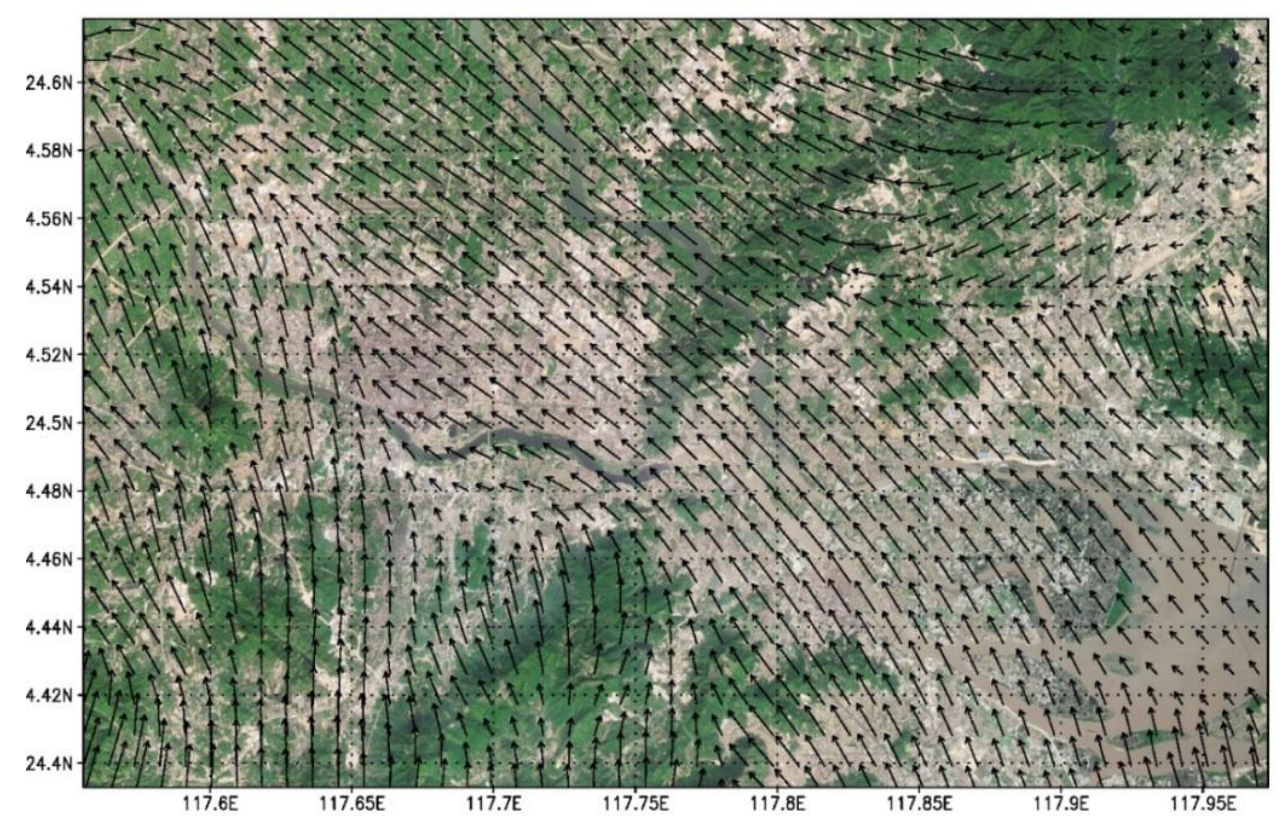

Figure 1. Zhangzhou Downtown Typical Summer Wind Field Map

\subsubsection{Mid-View Analysis}

On the mid-view level, this paper analyzes the ventilation potential in the urban linear space, focusing on ventilation performance of road and water. Through studies on the wind direction, speed and frequency in summer from Zhangzhou meteorological data, mainly according to Zhangzhou National Weather Station, this paper collects the frequency of various wind directions to have that the main wind direction in summer in Zhangzhou downtown is 30 degrees south of east and determines each level by every 22.5 degrees deviating from the prevailing wind. The angle of linear space including road and water regards the east as 0 degree, set in anti-clockwise and 
then to grade them to have the ventilation potential of major water and urban roads. The trends of water and road in Xiangcheng District, northwest of Longwen District, central area of Yuanshan New Town and northwest of Taiwanese Investment Zone are consistent with prevailing wind direction, while other districts possess poor ventilation potential.

\subsection{Delimit Wind Environment Compensation Area in the Premise of "Wind Formation"}

\subsubsection{Peripheral Compensation} Area

Cities locate in various peripheral environment. Wind circulation generally applying to the application of urban planning includes monsoon (season wind),

land and sea (lake) breeze and orographic wind generated from large scale water (ocean and lake). It is mainly monsoon and land and sea breeze according to the actual situation in Zhangzhou. Meteorology indicates summer monsoon in Zhangzhou downtown mainly consists of land and sea breeze from southeast to northwest and mountain and valley wind from south to north.

Corresponding to urban planning, delimit basic ecological lines for the control factors, such as large scale water, basic farmland, ecological forest, country park and nursery along the dominant direction included in the whole urban peripheral compensation area to ensure the integrity of ecological framework, total control of ecological land and feasibility for selection. Develop centralized protection to mountain in high elevation and with excellent natural plant coverage or water covering large area and surrounded by open terrain.

\subsubsection{Internal Compensation Area}

Based on the analysis of ventilation potential in the wind environment in the linear space, construct several urban parks (rain gardens) and water retarding areas along rivers and well ventilated primary and secondary roads in the city to compensate the air volume inside the city and along the ventilation corridor to ensure the flow and velocity of wind. Based on the urban greenbelt system planning combined with the practice in Zhangzhou, construct the overall structure of internal compensation areas in Zhangzhou consisting of large and middle parks and greenbelts and water in the city by combining wind environment characteristics and potential ventilation corridor in Zhangzhou.

\subsection{Delimit Wind Environment Active Region by the Heat Island Effect}

The active region of wind environment is the body of our city, and also the functional groups making up the city. The difference of the dominant functions, development strengths and surroundings of different groups reflects different differences in a small size, while the distinct temperature difference in the suburbs and center of the city is sensed by residents frequently. ${ }^{[7]}$

In the course of the project, the project team, through GIS, Natural Jenks (natural break method), analyzed the current architectural elements of the central urban area (building density, building volume density and building ventilation potentials), inverted the surface temperature, ground roughness and heat island intensity (the changing situation of surface temperature of winter and summer in the central urban area in recent five years) to delimit current heat island area, and analyzed the influence of all the parameters (see Figure 2). On the basis of status quo analysis, the planned and confirmed type of land use, functional layout, city development strength and organized city design were overlaid correspondingly to derive the potential heat island area. Prediction aiming at the current heat island area in the central urban area and potential heat island in the future development were made in advance, so that solution could be putting forward. In implementation, the ventilation performance, heat island situation, land using characters and city planning and construction of the central urban area are combined to set the priority of the active region. 


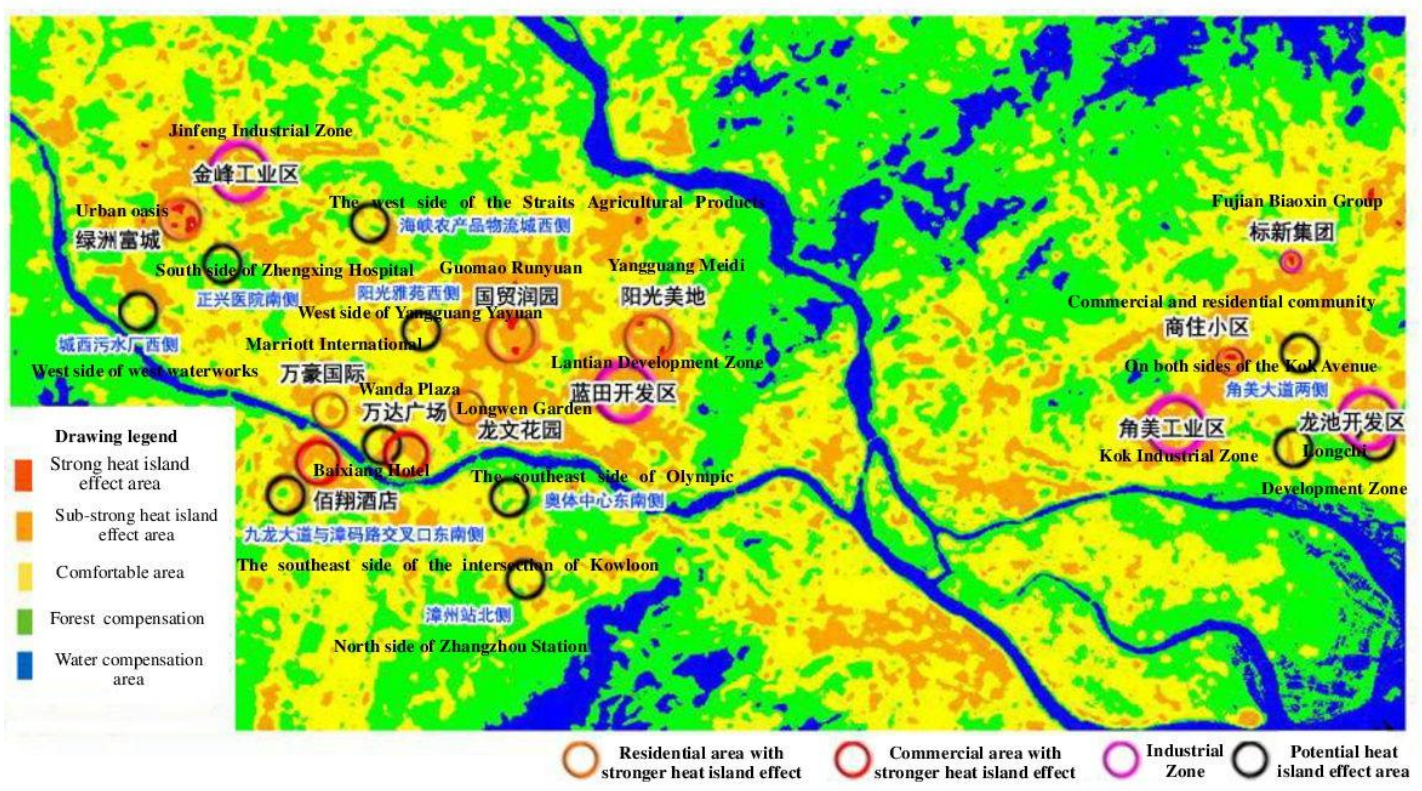

Figure 2. Profile of the Urban Heat Island

\subsection{Delimit Ventilation Corridor with Gallery Control as the Core}

\subsubsection{Classification and Guidance of Ventilation Corridor}

The urban ventilation corridors were classified for guidance according to the source of wind, air quantity and predominant wind direction; different cities could be divided into different classifications. Ventilation corridor classification was made according to different types of the cities. For example, in the ventilation corridor planning of
Zhangzhou, ventilation corridors are divided into two classes. Wherein the first class ventilation corridor is land and sea breeze formed by the air pressure difference between sea and land, which mainly blows sea breeze in day time; And blows land breeze at night. It mainly consists of the sea area in the east and southeast part of the central urban area and the regions along Jiulong River, including two ventilation corridors, namely Xixi and Beixi. Its main point of guidance is, on the basis of satisfying the requirement of water conservancy and flood prevention planning, controlling the concession of urban land use and the land usage character along the line. The second class ventilation corridor includes all kinds of channel parallel with or having rather small included angle with the direction of the urban yearly prevailing wind in medium level, such as main stems with rather high level and small pollution in the urban area, major public greenbelt, square and water series in the city. ${ }^{[8]}$ The width of the ventilation corridor, the requirement of the retreating green line and the guidance of the development strength around should be emphatically controlled (see Figure 3). 


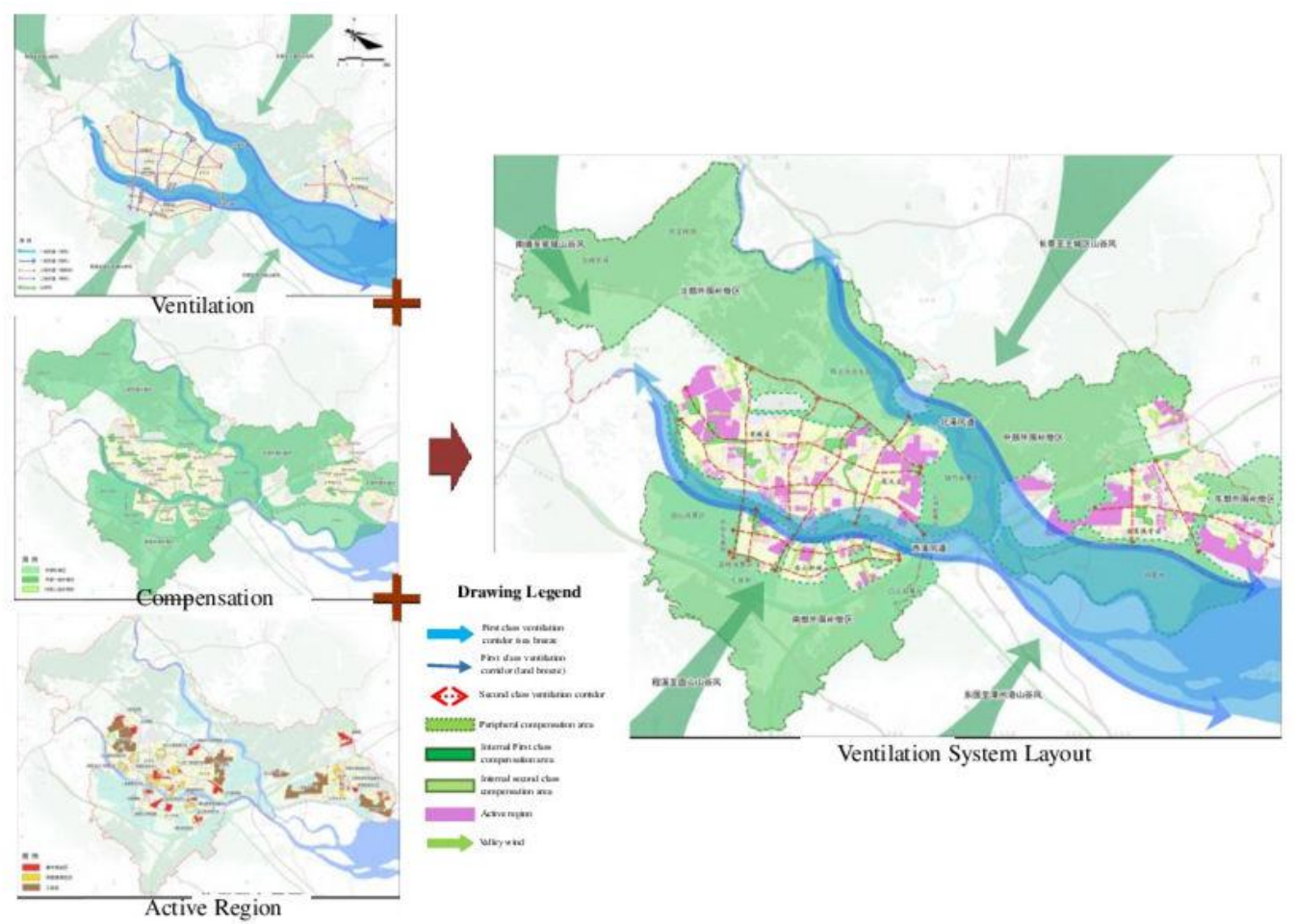

Figure 3. Derived Planning Graph of the Ventilation System Layout

\subsubsection{The Demarcation of Ventilation Corridor Control Elements}

There are many elements to affect the wind environment in cities.
This text, by combining the wind environment model in Zhangzhou for analysis and starting with the controllable angle of real city planning and management, preliminarily confirmed ventilation corridor, corridor width, building layout, building indicator and greening guide to make different guidance with the combination of the setting up of ventilation corridors of different classes. (see Table 1)

Table 1. List of Major Control Elements

\begin{tabular}{|c|c|c|}
\hline Control elements & Control main points & Control guideline \\
\hline Ventilation corridor & $\begin{array}{l}\text { Selection and control of the } \\
\text { urban land of ventilation } \\
\text { corridor }\end{array}$ & $\begin{array}{l}\text { The urban land character of the ventilation corridor should } \\
\text { be strictly controlled; projects with heavy air pollution } \\
\text { currently of the ventilation corridor should be removed and } \\
\text { negative list of the project should be set. }\end{array}$ \\
\hline Corridor width & Width and openness & $\begin{array}{l}\text { Width of the first class ventilation corridor } \geq 500 \mathrm{~m} \text {, and the } \\
\text { openness is total-open type; width of the second class } \\
\text { ventilation corridor } \geq 60 \mathrm{~m} \text {, and the openness is the } \\
\text { combination of open type and semi open type. }\end{array}$ \\
\hline Building layout & $\begin{array}{l}\text { Relations between buildings } \\
\text { and predominant wind } \\
\text { direction, and building face } \\
\text { width }\end{array}$ & $\begin{array}{l}\text { Buildings vastly and directly facing the predominant wind } \\
\text { direction should be absolutely avoided. Under the condition } \\
\text { of guaranteeing the buildings facing a good direction, the } \\
\text { longer side should be paralleled with the southeast wind as } \\
\text { far as possible and the maximum angle of deviation should } \\
\text { be controlled within } 30^{\circ} \text {. The projection of the largest } \\
\text { continuous face width of the residential building should not } \\
\text { be larger than } 45 \text { meters. }\end{array}$ \\
\hline Building layout & $\begin{array}{l}\text { Building density and building } \\
\text { height }\end{array}$ & $\begin{array}{l}\text { Building density in the first class ventilation corridor } \\
\leq 20 \% \text {, and building density in the } 300 \mathrm{~m} \text { buffer zone } \\
\text { outside the ventilation corridor } \leq 25 \% \text {. Building height in } \\
\text { the first class ventilation corridor } \leq 12 \mathrm{~m} \text {, and building } \\
\text { height in the } 300 \mathrm{~m} \text { buffer zone outside the ventilation } \\
\text { corridor } \leq 24 \mathrm{~m} \text {. Building density in the second class } \\
\text { ventilation corridor } \leq 25 \% \text {, and building density in the } 60 \mathrm{~m}\end{array}$ \\
\hline
\end{tabular}




\begin{tabular}{|l|l|l|}
\hline & & $\begin{array}{l}\text { buffer zone outside the ventilation corridor } \leq 30 \% . \\
\text { Building height in the second class ventilation corridor and } \\
60 \mathrm{~m} \text { buffer zone outside the second class ventilation } \\
\text { corridor should be controlled in } \leq 36 \mathrm{~m} .\end{array}$ \\
\hline Greening guide & $\begin{array}{l}\text { Suitable local plant types should be taken into } \\
\text { consideration for reasonable allocation; group planting } \\
\text { form should be adopted in the winter upwind to resist cold } \\
\text { wind; and rank-style planting form should be adopted } \\
\text { paralleled with the prevailing wind on the ventilation } \\
\text { planting proportion of theer in summer to guide the direction of wind; arbor, } \\
\text { and bushes } \\
\text { bush and grass of the greenbelt should account for a } \\
\text { proportion of 3:3:4. 99] }\end{array}$ \\
\hline
\end{tabular}

\subsection{Control of Planning and Result Expression}

Aiming at the ventilation corridor of different classes, the planning worked out elements like ventilation corridor width, access projects, building layout, greening requirement, etc, and expressed in the form as per requirement and control guideline. The control elements are mainly quantitative index, with control requirement of necessity; the control rules are mainly qualitative requirements, with control guideline of generalization. $^{[10]}$ Xixi ventilation corridor planning first class ventilation corridor in Zhangzhou ventilation corridor (Mazhou Bridge-Jinfeng Bridge) and Yuanguang South Road ventilation corridor of the second class ventilation corridor are selected as typical examples for the research. Rules were made for the control of current and potential heat island of smaller size in the planning, which provided technical reference for arranging reasonable greening, confirming block development strength and examining street interface scientifically. Bring ventilation corridor control requirement into urban technology control regulation and implement it through controlling elements related to the building on control and planning.(see Figure 4,5)

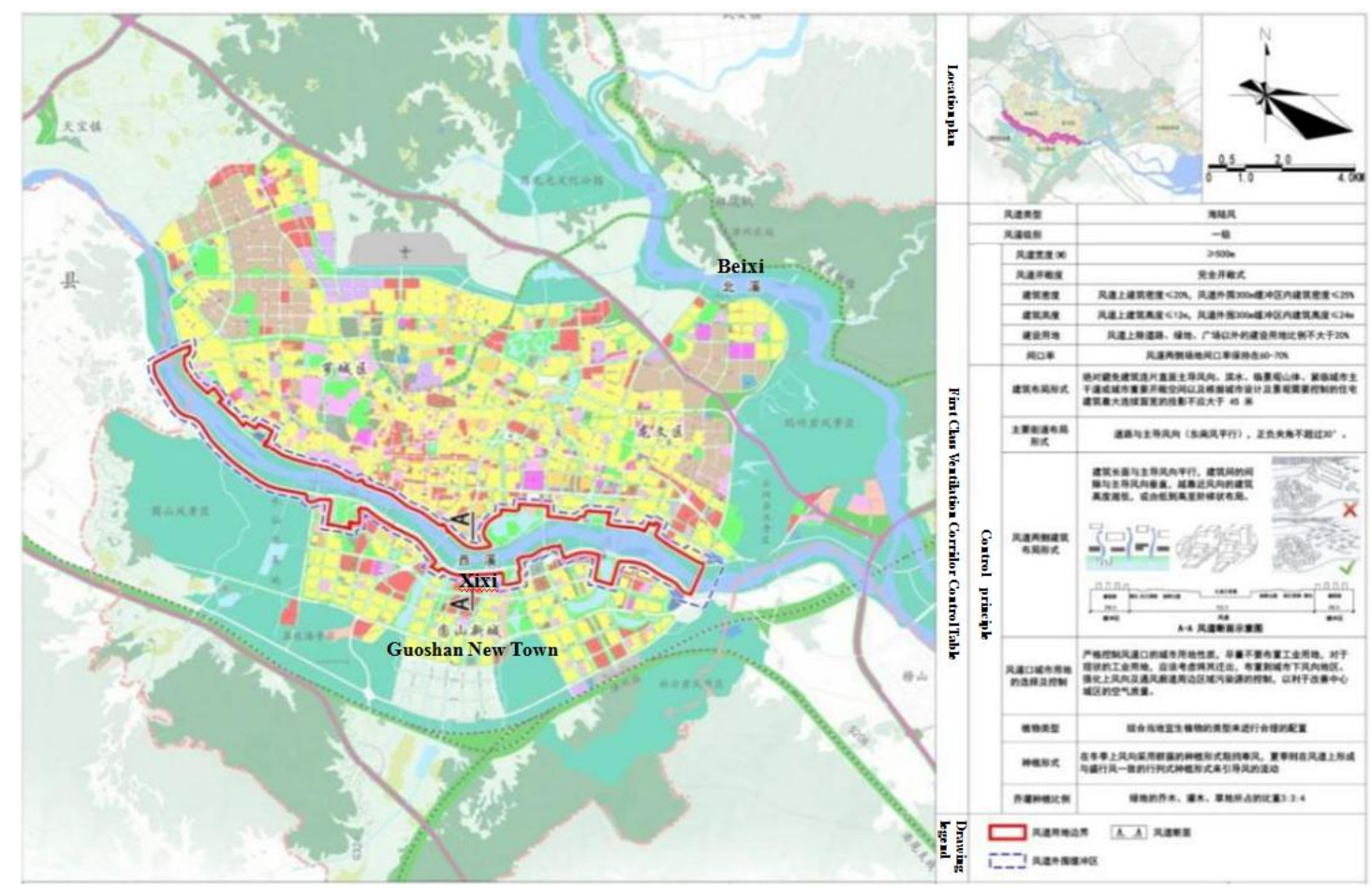

Figure 4. Controlling and guiding map of the first class ventilation corridor (Xixi ventilation corridor) 


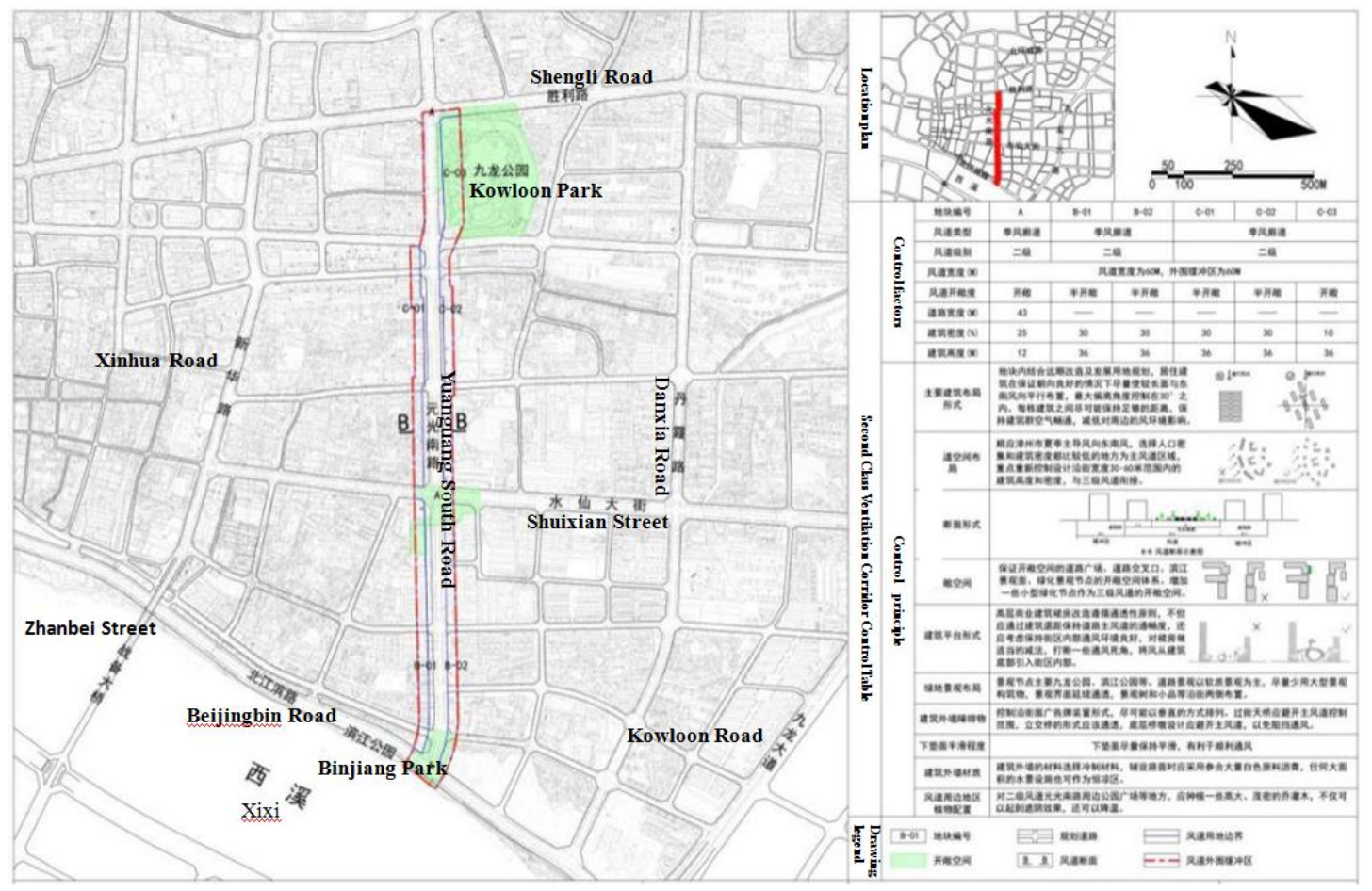

Figure 5. Controlling and guiding map of the second class ventilation corridor (Yuanguang South Road ventilation corridor)

\section{Conclusion}

In the process of rapid urbanization in our country, urban climate issues have been happening frequently in recent years because of the lack of prospective climate planning; the programming of ventilation corridor planning would be a helpful attempt to solve the urban environmental issue at one time. How to implement remedial measures for the built area and how to explore the climate planning and controlling strategy of the newly-built area to build a set of control system of the ventilation system confirming to the development of cities would be issues needing conscientious thinking for the planning employees in the new period.

\section{References}

[1] Jun Li, Ying Rong. Urban Ventilation Corridor Construction and its Design Control Guidance in Wuhan $[\mathrm{J}]$. Planner, 2014(8):115-120. (in Chinese)
[2] Chao Ren, Chao Yuan, Zhengjun $\mathrm{He}$ et al. Urban Ventilation Corridor Research and it Planning and Application [J]. Urban Planning Forum, 2014(3):52-60. (in Chinese)

[3] Yalan Zhu. Analysis of Integral Construction Model of Urban Air Duct [J]. Urban and Rural Construction, 2017(3):47-49.(in Chinese)

[4] Guangtao Wang, Xiaoyun Wang, Shiguang Miao et al. Research and Application of Urban Planning Atmospheric Environment Multiple Scaling Assessments Technological System [J]. Science China (D: Scientia Sinica Terrae), 2005,S1:145-155. (in Chinese)

[5] Xiaoyu Zhang, Riming Hao, Mingjuan Zhang. Basic Research on Urban Ventilation Channel Planning [J]. Environmental Science and Technology, 2014(S2):257-261.(in Chinese)

[6] Qingming Zhan, Wanlu Ouyang, Zhicheng Jin and $\mathrm{Li}$ Zhang.
Urban Ventilation Potential Research and Planning Guidance Based on RS and GIS [J]. Planner, 2015(11):95-99.(in Chinese)

[7] Shaolin Peng, Kai Zhou, Youhua Ye. Advances in Research of Urban Heat Island Effect [J]. Ecology and Environmental Sciences, 2005, 14(4):574-579.(in Chinese)

[8] Guangfeng Wang. Discussion on Urban Air Duct Construction Planning [J]. China Municipal Engineering, 2016(6):10-11.(in Chinese)

[9] Xiaomei Zhang. On Guidelines for the Planning and Control of Urban Road Greening $[\mathrm{J}]$. Building and Environment, 2009(4):137-138.(in Chinese)

[10] Chen Shaoqing, Liao Yi and Lin Chen. Urban Ventilation Corridor Planning Exploration under Multi-Dimension Control Angle China City Planning [C]. Annual Nation Planning Conference, 2016. (in Chinese) 